\title{
Non-constant Hazard Function and Inflation Dynamics
}

\author{
Fang Yao* \\ Universität Erlangen-Nürnberg and CRC 649 "Economic Risk"
}

September 6, 2011

\begin{abstract}
This paper presents some general results regarding the implications of the price reset hazard function for inflation dynamics. I first derive analytical results in a simple setup, showing that the shape of the price-duration distribution determines the shape of impulse responses of inflation. This result also holds under a more realistic setup with strategic complementarity, forward-looking IS curve and the Taylor rule in the numerical solution. I find that, under an increasing hazard function calibrated using the survey data, the model generates a hump-shaped impulse response of inflation to a monetary policy shock. In addition, thanks to the endogenous inflation inertia introduced by the flexible hazard function, the increasing-hazard model achieves a better inflation-output trade-off than the Calvo model in facing a cost-push shock.
\end{abstract}

JEL classification: E31; E52

Key words: Hazard function, Sticky Prices, Inflation inertia, Monetary Policy

${ }^{*}$ I am grateful to Michael Burda, Carlos Carvalho, Ryan Chahrour, Alexander Meyer-Gohde, Kevin Sheedy, Joseph Vavra and Alexander Wolman, and all other seminar participants for helpful comments in Berlin, Nashville, Richmond and New York. I acknowledge the support of the Universität Erlangen-Nürnberg and the Deutsche Forschungsgemeinschaft through the CRC 649 "Economic Risk". All errors are my sole responsibility. Address: Chair of macroeconomics, Universität Erlangen-Nürnberg, Lange Gasse. 20, 90403 Nürnberg, Germany +499115302319, email: fang.yao@wiso.uni-erlangen.de 


\section{Introduction}

This paper studies the implications of the price reset hazard function for inflation dynamics and monetary policy. A price reset hazard function specifies the probability of resetting a price conditional on the time elapsed since the last adjustment. The shape of hazard function is important for aggregate dynamics, because it determines the distribution of prices, which in turn affects how the economy reacts to nominal disturbances. With a few exceptions ${ }^{1}$, most theoretical sticky price models base their positive or normative implications on a particular shape of hazard functions. For instance, Calvo (1983) assumes a constant hazard function, Taylor (1980) postulates the probability of price adjustment to be either zero or one, while menu cost models (e.g. Dotsey et al., 1999, Golosov and Lucas, 2007) imply an increasing hazard function.

In this paper, I focus primarily on the effects of the price reset hazard function on the impulse response function of inflation to a monetary policy shock. It is well known in monetary economics that it is difficult to get a hump-shaped impulse response of inflation to a monetary policy disturbance. This paper emphasizes the important role of the price distribution in bridging the price reset hazard function and the inflation response. I show analytically that the shape of the price distribution to a large extent determines the shape of the inflation response to a monetary shock. In the existing general-hazard literature (see: e.g. Mash, 2004, Whelan, 2007, and Sheedy, 2010), the invariant distribution of price durations is commonly used. This distribution will be reached eventually, as long as there are no interruptions occurring to the stochastic adjustment process. Because the invariant distribution is always decreasing in price durations regardless of the shape of hazard functions, the inflation response in these models is typically monotonic decreasing. By contrast, I consider an economy, in which the invariant distribution can not be reached. In reality, there are many reasons to make this case interesting. For example, price adjustments are caused by constantly idiosyncratic as well as aggregate shocks. Presumably firms react to idiosyncratic shocks (perfectly observable) every period, but, due to imperfect information, they can not optimally reset their prices in response to a monetary shock. As a result, the price adjustment to idiosyncratic shocks synchronizes all prices each period, so that the price-duration distribution can never converge to the invariant distribution. In this case, the price distribution would follow a "transient" distribution, which differs substantially from the invariant distribution.

In section 3, I apply the statistical duration analysis to derive the transient distribution of price durations under a history-dependent price adjustment process. The key difference between these two distributions is: while the invariant distribution is always decreasing in price durations, the transient distribution allows for a wide range of shapes. When the hazard function is constant, the transient distribution of price durations is downward-sloping. Under an increasing hazard function, however, it attains a bell-shape. The shape of the price-duration distribution is important in sticky price models, because it affects the aggregation mechanism of the economy, and therefore the response of aggregate price and inflation to monetary policy shocks. To this end, I present two analytical results in a simple sticky price model with flexible hazard functions. These results link the shape of the price-duration distribution and the impulse

\footnotetext{
${ }^{1}$ See: e.g. Wolman (1999), Mash (2004) and Sheedy (2010).
} 
responses of inflation to a monetary disturbance. In particular, I show that the shape of the impulse responses of inflation is determined both by the rate at which the exogenous shock decays over time $\rho$ and the distribution of price durations $\theta_{j}$. The intuition of this result is that, $\rho$ affects the size of responses to the shock over time, while $\theta_{j}$ determines the fraction of firms adjusting their prices. In a special case, where the shock is permanent $(\rho=1)$, the shape of the impulse response is solely dictated by the shape of price-duration distribution.

Section 4 extends the simple setup to a more complex case by considering strategic complementarity in price-setting, the intertemporal IS curve and monetary policy feedback rules. Using the numerical solution, I show that the intuition drawn from the analytical results also holds in this more realistic model. In particular, when calibrating the hazard function based on the survey evidence by Blinder et al. (1998), the impulse response function of inflation has a humped shape, which is consistent with the structural VAR evidence reported by Christiano et al. (2005). Mankiw and Reis (2002) compare the impulse responses generated by the Calvo sticky price model with those from the sticky information model. They conclude that the sticky information model outperforms the Calvo sticky price model because the sticky price model generates a hump-shaped response of inflation, but the Calvo model only predicts a monotonic response. In the light of my analysis, the monotonic inflation response is not an intrinsic feature of sticky price models, rather merely results from the restrictive hazard function underlying the Calvo assumption. ${ }^{2}$

In the last part, I also study the model's response to a cost-push shock under the Taylor rule. I find that the increasing-hazard model achieves a better trade-off between inflation and output than the Calvo model, because the increasing hazard function gives the model a new source of endogenous inflation inertia, which is missing in the Calvo setup. The endogenous inflation persistence makes inflation to be strongly anchored to his own past, so that the nominal interest rate needs not to be raised as aggressively as in the Calvo case in facing a positive cost-push shock. Moreover, I find that the forward-looking interest rule is superior to the contemporary rule under both constant and increasing hazard functions.

The remainder of the paper is organized as follows: in section 2, I discuss the related literature; section 3 presents the simple sticky price model with the generalized hazard function and derives analytical results; in section 4 , I extend the model to a more realistic case and solve the model numerically. I present the numerical results in impulse response function plots; section 5 contains some concluding remarks.

\section{Related Literature}

Given the prominent position of the Calvo pricing models in monetary economics, many authors have already questioned the robustness of the implications of the Calvo setting. Pioneer work by Wolman (1999) extends the basic Calvo price-setting to the general hazard case. In a partial equilibrium analysis, he shows that inflation dynamics are sensitive to the hazard function underlying different pricing rules. Kiley (2002) compares the Calvo and Taylor staggered-pricing models, and finds that the dynamics of output following monetary shocks are both quantitatively and qualitatively different across the two pricing specifications unless one assumes a substantial

\footnotetext{
${ }^{2}$ For more detailed comparison of those two models, see Yao (2011).
} 
level of real rigidity in the economy. Mash (2004) derives the generalized New Keynesian Phillips curve, and shows that this model can reconcile the tension between evidence on inflation inertia at the macro level and the frequent price-setting at the micro level. Whelan (2007) studies inflation persistence under the general form of hazard functions as in Mash (2004). He shows that the generalized New Keynesian Phillips curve has negative coefficients on lags of inflation regardless of the shape of the hazard function. Sheedy (2010) focuses on the role of the shape of hazard functions in forming "intrinsic inflation persistence". He parameterizes the hazard function using a recursive formulation and shows that, under this parameterization, upwardsloping hazard functions lead to positive coefficients on lags of inflation in the theoretical Phillips curve. In this paper, I focus on the implications of hazard functions for short-run inflation dynamics. My approach differs from the general-hazard models in the existing literature in that it applies a price-duration distribution which is more suitable for the short-run analysis, such as the impulse response method.

This paper is also related to heterogeneous price stickiness literature. Carvalho (2006) extends the simple Calvo model to the general case, allowing for different sticky price sectors having heterogeneous price adjustment rates. He finds that the generalized Calvo model can generate inflation inertia, but it fails in predicting the hump-shaped inflation response. Dixon and Kara (2010) generalize the fix-duration Taylor contract model by introducing a distribution of contract lengths using micro data. In order to generate a significant hump-shaped inflation response, their model needs a mean contract duration as long as 7 quarters, which is at odds with the mean duration in the micro data. Even though my model does not consider the effect of heterogeneity in price stickiness, it provides insights to understand the results of heterogeneous sticky price models. The key insight from my analysis is that the shape of an inflation impulse response function is primarily determined by the pricing behavior at the firm's level. Aggregation of sticky-price sectors with different mean durations would not fundamentally change the shape of inflation response. In this paper, I show that sticky price-setting at the firm's level, which is characterized by an increasing hazard function, is essential for generating a prominent hump-shaped impulse response of inflation. When the pricing behavior at the firm's level follows the Calvo staggering scheme, there is no hope to get a humped shape by aggregating heterogeneous sticky price sectors. Similarly, the simple Taylor model generates only a jagged impulse response of inflation at the firm's level. ${ }^{3}$ As a result, aggregating those jagged responses has also difficulty in replicating a significant humped response of inflation to a monetary policy shock.

\section{The Model}

In this section, I do not explicitly model the micro foundation of price stickiness in the face of the monetary disturbance. Instead, I present a stylized sticky price model under a general price reset hazard function. Thanks to the simplicity of the model, I can present analytical results, which shed lights on the key mechanism at work. In the following, I first describe the price adjustment process under a general hazard function and derive the transient distribution of price durations. This general price staggering scheme is then applied to the sticky-price model.

\footnotetext{
${ }^{3}$ Note that the simple Taylor model possesses an extreme form of increasing hazard function. It is either zero during the contract or one at the end of the contract.
} 


\section{Hazard Function and Price-duration Distribution}

I consider an economy, in which monopolistically competitive firms can not adjust their prices optimally every period in response to aggregate shocks. Instead, all firms face identical probabilities of reoptimizing their prices, which are summarized by a hazard function

$$
h_{i}=P(\text { adjust at } i \mid \text { survival to } i-1) \text {. }
$$

The hazard function gives the probability of adjusting a price at the $i$ th period since the last price adjustment conditional on the price has been fixed for $i-1$ periods, $\forall i=0,1, \cdots, I$. I is the maximum possible price duration, which is possibly infinite. At this stage, I only restrict the hazard function to be $0 \leqslant h_{i} \leqslant 1, \forall i$, for having a well-defined hazard function in the discrete-time model.

I also define the survivor function, $S_{i}=\prod_{j=0}^{i}\left(1-h_{j}\right)$, which gives the probability of a price being fixed at least for $i$ periods. Furthermore, the distribution function is obtained by $F_{i}=$ $1-S_{i}$. Table (1) summarizes key notations of this stochastic adjustment process.

\begin{tabular}{|c|c|c|c|}
\hline Duration & Hazard Function & Survival Function & Distribution Function \\
\hline \hline$i$ & $h_{i}$ & $S_{i}$ & $F_{i}$ \\
\hline 0 & 0 & 1 & 0 \\
1 & $h_{1}$ & $1-h_{1}$ & $1-S_{1}$ \\
$\vdots$ & $\vdots$ & $\vdots$ & $\vdots$ \\
$i$ & $h_{i}$ & $\prod_{j=0}^{i}\left(1-h_{j}\right)$ & $1-S_{i}$ \\
$\vdots$ & $\vdots$ & $\vdots$ & $\vdots$ \\
\hline
\end{tabular}

Table 1: Notations of the stochastic adjustment process in the discrete time

Based on these notations, I can derive the probability mass function $\left(\theta_{i}\right)$, which gives the probability of price adjustment at $i$ periods after the last revision. When there is a large number of firms in the economy, this probability also equals the fraction of firms that change their prices at the $i$ th period after their last adjustment, so that we can use it as the distribution of price durations. It is easy to derive the probability mass function by subtracting two successive distribution functions

$$
\begin{aligned}
\theta_{i} & =F_{i+1}-F_{i} \\
& =S_{i}-S_{i+1} \\
& =\prod_{j=0}^{i}\left(1-h_{j}\right)-\prod_{j=0}^{i+1}\left(1-h_{j}\right) \\
& =h_{i+1} \prod_{j=0}^{i-1}\left(1-h_{j}\right), \quad \forall i=0,1, \cdots .
\end{aligned}
$$

I call (1) the transient distribution, because it needs all prices in the economy to be synchronized every period, so that they are all in the duration group zero when this history dependent 

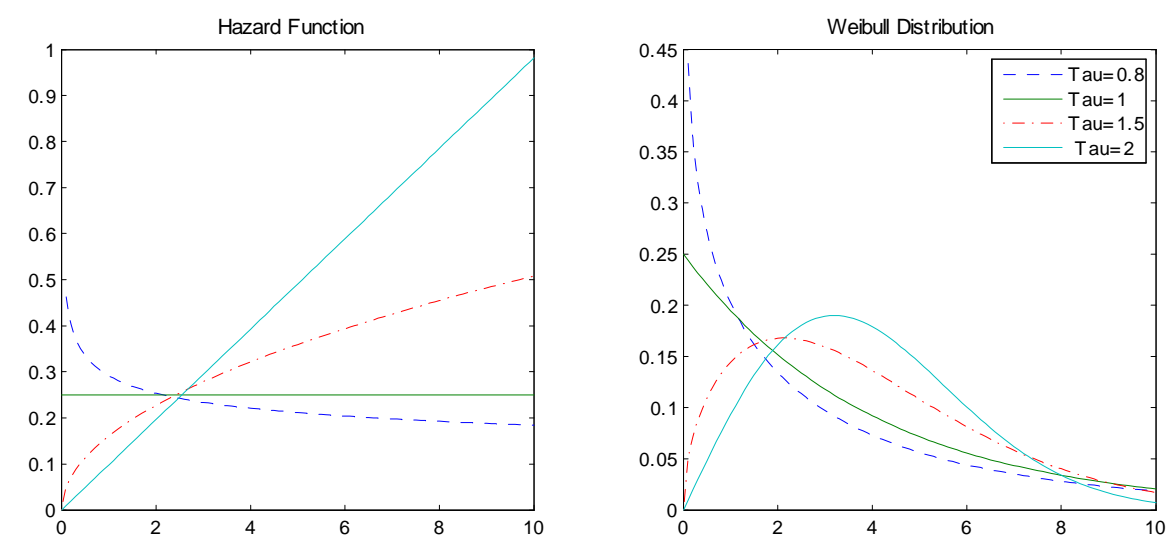

Figure 1: The hazard function and distribution of durations of the Weibull distribution

price adjustment process gets restarted at each period. Without the synchronization mechanism, the distribution will eventually converge to the invariant distribution used by the existing literature.

Based on (1), the transient distribution attains different shapes under different hazard functions. For example, under a parametrization of the Weibull distribution, as shown in figure (1), when the hazard function is constant, the price durations are exponentially distributed, while, under an increasing hazard function, the price-duration distribution is bell-shaped.

The shape of the price-duration distribution has important normative and positive implications in the sticky price models. For optimal monetary policy, Woodford (2003) shows how price dispersion affects the welfare-based loss function of central banks. As for the positive implication, in the following, I present some analytical results linking the shape of the priceduration distribution directly to the impulse response functions of aggregate price and inflation to a nominal shock.

\section{The Generalized Sticky-Price Model}

In this section, I present a highly stylized sticky price model to deliver analytical results. I will check the robustness of those results in a more realistic model in the numerical exercise.

First, I assume that, in each period, the log of nominal marginal costs is determined by aggregate price and output gap

$$
m c_{t}=p_{t}+\omega y_{t}
$$

where $p_{t}$ denote the logarithm of aggregate price and $y_{t}$ is the output gap, the percentage deviation between output and potential output. The output gap elasticity $\omega$ can be interpreted as the degree of strategic complementarity in the price-setting among firms. As discussed in Woodford (2003), this parameter can be motivated by a model with specific factor markets (Altig et al., 2005) or the decreasing elasticity of demand for production (Kimball, 1995). When $\omega$ is smaller than one, marginal cost of an adjusting firm does not react proportionally to the aggregate demand condition. 
When a firm resets its price, the optimal price chosen should reflect the probability that the reset price will be fixed at least for $j$ periods. These possibilities are given by the survival function $S_{j}$, defined in table (1). The optimal price $x_{t}$ in the sticky price model is given by ${ }^{4}$

$$
x_{t}=\sum_{j=0}^{\infty} \frac{S_{j}}{\sum_{j=0}^{\infty} S_{j}} E_{t}\left[m c_{t+j}\right] .
$$

The intuition of this equation is that the optimal price is set such that it exactly compensates a weighted sum of current and future marginal costs, and the weights are determined by the survival function.

As discussed in the preceding section, given any price reset hazard function, the distribution of prices in the economy is determined by equation (1). As a result, logarithm of the aggregate price level $p_{t}$ is a weighed average of all optimal prices chosen in the past and the weight is equal to the probability mass of each price duration

$$
p_{t}=\sum_{j=0}^{\infty} \theta_{j} x_{t-j}
$$

To close the model, I assume that nominal aggregate demand is following a quantity-theory equation

$$
m_{t}=p_{t}+y_{t},
$$

where $m_{t}$ is the log of nominal money supply, which is exogenously determined by the monetary authority. Furthermore, the monetary authority is assumed to control nominal money supply either in levels or in the rate of growth, whose recursive laws of motion are as follows

$$
\begin{aligned}
m_{t}= & \rho m_{t-1}+\epsilon_{t}, \\
& o r \\
\Delta m_{t}= & \rho \Delta m_{t-1}+\epsilon_{t}, \\
\text { where } \epsilon_{t} & \sim \text { i.i.d. }\left(0, \sigma_{m}^{2}\right) .
\end{aligned}
$$

\section{Impulse Response Function and Distribution of Price Durations}

In this section, I focus on the model without strategic complementarity in the price-setting. It amounts to setting $\omega=1$. The exercise not only allows me to disentangle effects of nominal rigidity from those of real rigidity, but also to present the analytical solution of the impulse response function. In the next section, I will solve a more realistic setup allowing for strategic complementarity and discuss the result.

When $\omega=1$, the sticky-price model can be simplified into two-equation systems, taking $m_{t}$

\footnotetext{
${ }^{4}$ This equation can be formally derived from a firm's profit maximization problem. To keep the analysis as simple as possible, without losing generality, the subjective discount factor $\beta$ is set to be one in this equation. For details, see Yao (2009).
} 
as exogenously given by equation (6) or (7).

$$
\begin{aligned}
& x_{t}=\sum_{k=0}^{\infty} \frac{S_{k}}{\sum_{k=0}^{\infty} S_{k}} E_{t}\left[m_{t+k}\right] \\
& p_{t}=\sum_{j=0}^{\infty} \theta_{j} x_{t-j} .
\end{aligned}
$$

Proposition 1 Assume that nominal money supply follows an AR(1) process specified in (6). Under the sticky-price model summarized by equation (8) and (9), up to first-order approximation, the impulse response function of aggregate price to a money supply disturbance is given by

$$
\begin{aligned}
I R\left(p_{t+i}\right) & =\frac{\partial p_{t+i}}{\partial \epsilon_{t}}=\bar{F} \sum_{j=0}^{i} \theta_{j} \rho^{i-j}, \\
\text { where } \bar{F} & =\frac{\sum_{i=0}^{\infty} \rho^{i} S_{i}}{\sum_{i=0}^{\infty} S_{i}} .
\end{aligned}
$$

Proof: See Appendix (5).

Two important insights stand out from this result. First, there is a scaling factor $\bar{F}$ reflecting the forward-looking behavior embedded in the sticky-price model. In the sticky price model, firms can not adjust their prices every period, as a result, they take into account that the impact of the monetary disturbance is decaying over time at the rate of $\rho$. The optimal adjustment of prices is scaled down by the factor $\bar{F}$, because their prices would be otherwise inefficiently high, once the shock get weakened in the future. When $\rho=1$, meaning a permanent shock, the scaling factor is equal to one. In this case, the forward-looking motive in the sticky price model loses its significance.

Second, under an $A R(1)$ money level shock, the shape of the impulse responses of the price level is determined by the distribution of price durations $\theta_{j}$ and the rate at which the exogenous shock decays over time $\rho$. This is intuitive, because $\rho$ gives the size of responses to the shock, and the distribution of price durations $\theta_{j}$ determines the timing of those responses. This intuition can be better manifested by a special case, where the shock is permanent $(\rho=1)$. In this case, it doesn't matter when a price reacts to a shock, so that the size of the response is always the same. As a result, the shape of the impulse response is solely determined by the distribution of price durations. Formally, when $\rho=1$, then $\operatorname{IR}\left(p_{t+i}\right)=\sum_{k=0}^{i} \theta_{k}$.

Furthermore, the impulse response of inflation can be derived by subtracting two consecutive impulse responses of the price level

$$
\begin{aligned}
\operatorname{IR}\left(\pi_{t+i}\right) & =\operatorname{IR}\left(p_{t+i}\right)-\operatorname{IR}\left(p_{t+i-1}\right) \\
& =\left[\sum_{k=0}^{i} \theta_{k}-\sum_{k=0}^{i-1} \theta_{k}\right] \\
& =\theta_{i}
\end{aligned}
$$


In this case, the impulse response of inflation to a money level shock is exactly equal to the distribution of price durations. ${ }^{5}$

Next, I show that the similar insights can be drawn from the impulse response of inflation to the money growth shock.

Proposition 2 Assume that nominal money supply growth rates follow an $A R(1)$ process specified in (7). Under the sticky-price model summarized by equation (8) and (9), up to a firstorder approximation, the impulse response function of inflation to a money growth disturbance is given by

$$
\begin{aligned}
I R\left(\pi_{t+i}\right) & =\frac{\partial \pi_{t+i}}{\partial \epsilon_{t}}=\bar{F} \sum_{j=0}^{i} \theta_{j} \rho^{i-j}, \\
\text { where } \bar{F} & =\frac{\sum_{i=0}^{\infty} \rho^{i} S_{i}}{\sum_{i=0}^{\infty} S_{i}} .
\end{aligned}
$$

Proof: See Appendix (5).

This is a parallel result to proposition 1 . First, the scaling factor $(\bar{F})$ reflects the forwardlooking behavior in the sticky-price model. The impulse response of inflation would be lower, if firms expect money growth disturbances decay over time. Second, the shape of impulse responses is determined by the distribution of price durations $\theta_{j}$ and the rate at which the exogenous shock decays over time $\rho$. Under a permanent nominal money growth shock, impulse responses of inflation are dictated by the shape of price distribution. Formally, when $\rho=1$, equation (11) yields

$$
\operatorname{IR}\left(\pi_{t+i}\right)=\sum_{j=0}^{i} \theta_{j}
$$

One can also show that the change of the impulse response of inflation to a money growth shock can be obtained by

$$
\begin{aligned}
\Delta I R\left(\pi_{t+i}\right) & =\operatorname{IR}\left(\pi_{t+i}\right)-I R\left(\pi_{t+i}\right) \\
& =\bar{F}\left[\theta_{i}-(1-\rho) \sum_{j=0}^{i-1} \theta_{j} \rho^{i-1-j}\right] .
\end{aligned}
$$

When the impulse response function is hump-shaped, we need $\Delta I R\left(\pi_{t+i}\right)$ to be positive at some $i$. It means that $\theta_{i}$ should be larger that $(1-\rho) \sum_{j=0}^{i-1} \theta_{j} \rho^{i-1-j}$. This would be more likely when the price distribution $\theta_{i}$ is also increasing on the same interval of the time horizon.

To sum up the analytical results, I have shown that, in the sticky-price model, inflation persistence comes from two sources. One is directly from persistence of the exogenous shock, while the other source stems from the staggering price-setting, summarized by the distribution of price duration. Increasing hazard functions give the model a stronger internal propagation for inflation dynamics than the Calvo assumption.

\footnotetext{
${ }^{5}$ Vavra (2010) shows the same result under a more general framework.
} 


\section{Numerical Results}

In this section, I study the intuition gained from the simple setting under a more realistic model. Specifically, I add the following new features into the basic framework: strategic complementarity in price-setting, an expectational IS curve and an interest rate rule.

$$
\begin{aligned}
E_{t}\left[y_{t+1}\right]-y_{t}= & i_{t}-E_{t}\left[\pi_{t+1}\right], \\
p_{t}= & \sum_{j=0}^{J} \theta_{j} x_{t-j}, \\
x_{t}= & \sum_{j=0}^{J} \frac{S_{j}}{\sum_{j=0}^{J} S_{j}} E_{t}\left[m c_{t+j}\right], \\
m c_{t}= & p_{t}+\omega y_{t}+u_{t}, \\
u_{t}= & \rho_{u} u_{t-1}+v_{t}, \quad \text { where } v_{t} \backsim i . i . d .(0,1) \\
\pi_{t}= & p_{t}-p_{t-1}, \\
i_{t}= & \alpha i_{t-1}+(1-\alpha)\left[\phi_{\pi} \pi_{t}+\phi_{y} y_{t}\right]+\epsilon_{t}, \\
& \text { where } \epsilon_{t} \backsim i . i . d .\left(0, \sigma_{m}^{2}\right) .
\end{aligned}
$$

Equation (14) is the expectational IS curve. This equation can be obtained by log-linearizing the consumption Euler equation that arises from the household's optimal saving problem. $y_{t}$ denotes output gap, $i_{t} \equiv \log R_{t}$ is the nominal interest rate and inflation rate $\pi_{t} \equiv \log P_{t}-\log P_{t-1}$.

Equation (15) and (16) directly follow equation (3) and (4). The only change is that I restrict the maximum price duration to be finite. Without losing generality, let $J$ be the maximum possible duration, i.e. for a price which has lasted $J$ periods, the probability of price adjustment equals one. This assumption is mainly required by the numerical computation, but it is also realistic to expect that no price would last forever.

Equation (17) follows the assumption about nominal marginal cost in equation (2). Because the cost-push shock plays an important role in the optimal monetary policy literature, I add a cost-push shock to this equation to study the model's behavior under a specific policy rule.

Equation (19) is a simple interest rate rule, ${ }^{6}$ proposed by Taylor (1993), with interest rate smoothing. As discussed in Clarida et al. (1999), this rule is not only broadly consistent with the main principles for optimal monetary policy, but also provides a good empirical description of the U.S. monetary policy during the Volcker-Greenspan period (Clarida et al., 2000). Since, in this paper, I do not derive the policy rule in an optimizing sense, as a robustness check, I also solve the model with a forward-looking Taylor rule in the form

$$
i_{t}=\alpha i_{t-1}+(1-\alpha)\left[\phi_{\pi} E_{t} \pi_{t+1}+\phi_{y} y_{t}\right]+\epsilon_{t} .
$$

This form of the forward-looking rule is shown to be consistent with the optimal policy rule derived under the discretionary policy regime with inflation persistence (Clarida et al., 1999).

\footnotetext{
${ }^{6}$ Constant terms are ignored in the Taylor rule, because, up to first-order approximation, they do not affect dynamics of the model.
} 


\section{Calibration}

As the main theme of the paper suggested, the most important parameters in this model are those affecting the price reset hazard function. Empirical studies provide useful information on the average level of the hazard function, but very mixed message about the shape of the hazard function. For example, Cecchetti (1986) and Goette et al. (2005) find strong support for increasing hazard functions, while recent studies based on U.S. or European CPI data show that hazard functions are mainly flat or downward-sloping (see: e.g. Alvarez, 2007, Nakamura and Steinsson, 2008a and Klenow and Kryvtsov, 2008).

In the numerical exercises, I focus on increasing hazard functions due to the following reasons. First, the increasing hazard function is advocated by most of micro-founded sticky price models (See: e.g. Dotsey et al., 1999, Golosov and Lucas, 2007 and Nakamura and Steinsson, 2008b). For example, Nakamura and Steinsson (2008b) show in a menu-cost model that the shape of the hazard function is influenced by the relative size of transient and permanent shocks to marginal costs. Permanent shocks tend to yield an upward-sloping hazard function, while transient shocks cause the hazard function to flatten. A downward-sloping hazard function can only be generated when assuming unrealistic large temporary shocks to marginal cost. Second, some authors argue that the estimated downward-sloping hazards result mainly from the heterogeneity in price stickiness. As shown by Alvarez et al. (2005), the decreasing hazard function found in the CPI data could simply results from the aggregation bias due to heterogeneous hazard functions with different price durations. Based on this insight, I view that the evidence of downwardsloping hazards is rather an aggregation phenomenon, and therefore is less relevant to the pricing behavior at the firm's level. Since the main focus of the paper is to address how price stickiness at the firm's level affects aggregate dynamics, I will conduct my numerical analysis under increasing hazard functions motivated by micro-founded theoretical models. ${ }^{7}$

Following Mash (2004), I calibrate the hazard function based on the survey evidence by Blinder et al. (1998) for the U.S. economy. As reported in table (2), this empirical hazard function is increasing in price durations and the maximum price duration is truncated at the 7 th quarter ${ }^{8}$. In the numerical exercise, I compare this empirical hazard with the Calvo hazard function, which has a mean price duration of 3 quarters. This is consistent with the mean price duration of 7 - 9 months estimated by Nakamura and Steinsson (2008a). Given the hazard function, the survival function $S_{j}$ and the distribution of price durations $\theta_{j}$ can be calculated using formulae presented in table (1) and equation (1).

\begin{tabular}{c|l|l|l|l|l|l|}
\hline \hline Hazard Function & $h_{1}$ & $h_{2}$ & $h_{3}$ & $h_{4}$ & $h_{5}$ & $h_{6}$ \\
\hline Calvo (1983) & $1 / 3$ & $1 / 3$ & $1 / 3$ & $1 / 3$ & $1 / 3$ & $1 / 3$ \\
\hline Blinder et. al (1998) & 0.09 & 0.15 & 0.29 & 0.42 & 0.54 & 0.68 \\
\hline \hline
\end{tabular}

Table 2: Calibration of hazard functions

As for the remaining structural parameters, I set the real rigidity parameter $\omega$ to be 0.1 . As discussed in Woodford (2003), real rigidity can be motivated by different micro-foundations.

\footnotetext{
${ }^{7} \mathrm{My}$ model can be easily extended to the case, where heterogeneity in sticky pricess is allowed, but the main implication of the model will not be affected by this extension.

${ }^{8}$ This empirical hazard function is calculated by Mash (2004) in Table 1.
} 
The value I choose can be justified with a model with specific factor markets (Altig et al., 2005) or the decreasing elasticity of demand for production (Kimball, 1995). Finally, to facilitate the comparison with the SVAR evidence presented by Christiano et al. (2005), I choose the standard deviation of the shock to the Taylor rule to be $0.71 \%$, at an annual rate, which is estimated by Christiano et al. (1999) using the federal funds rate. The Taylor rule parameters are calibrated by using the point estimates, reported by Clarida et al. (2000). They show that the inflation response parameter $\phi_{\pi}$ is 2.15 , the output-gap response parameter $\phi_{y}$ is $0.93 / 4$ and the interest rate smoothing parameter $\alpha$ is 0.79 during the Volcker-Greenspan period (1979:3 - 1996:4).

\section{Impulse Responses to a Monetary Policy Shock}

In this section, I discuss the impulse response of inflation and output to the monetary policy disturbance. Figure 2 depicts the impulse responses to a one-standard-deviation expansionary monetary policy shock under the contemporary Taylor rule. I compare impulse response functions generated by the Calvo model with those from the survey evidence motivated increasing-hazard model.

The first noteworthy result from the figure is that models with increasing hazard rates generate hump-shaped impulse responses of inflation, while the Calvo model produces monotonic impulse responses. These results are consistent with the analytical analysis presented in previous section that the staggered price setting at the firm's level is an important source of inflation inertia. Technically, the shape of the impulse response function of inflation is predominated by the shape of price-duration distribution. Because the constant hazard function underlying the Calvo assumption gives rise to an exponentially distributed price duration, the response of inflation in the model is monotonic. By contrast, an increasing hazard function leads to a bellshaped distribution of price durations, and hence a hump-shaped response of inflation. As seen in the left panel, the impulse response of inflation peaks at the fourth period after impact. Even though the maximum impact on inflation is still not as pronounced as those empirical impulse responses in the structural VAR studies (see: e.g. Christiano et al., 1999, Christiano et al., 2005), it exhibits a significant improvement in comparison to the Calvo model. On the right panel, the shape of the hazard function does not affect the response of the output gap much. In both models, responses of the output gap increase at the impact of unexpected reduction of nominal interest rate, and then monotonically decline back to the steady state level.

In figure 3, I show the impulse responses of inflation and output to a one-standard-deviation expansionary monetary policy shock under the forward-looking Taylor rule. There is no qualitatively significant difference in the results comparing to the preceding case. Therefore, my conclusion is robust to the change from contemporary to forward-looking monetary policy rules.

The new insight for modeling of sticky prices from my analysis is that the shape of the inflation impulse response function is generally determined by the pricing behavior at the firm's level. Aggregation of heterogeneous sticky-price sectors would not fundamentally change the shape of inflation response. In this paper, I have shown so far that sticky price-setting at the firm's level, characterized by an increasing hazard function, is essential for generating a prominent hump-shaped impulse response of inflation. Furthermore, Mankiw and Reis (2002) showed that the sticky information model is superior to the Calvo sticky price model, because the latter fails in generating a hump-shaped impulse response of inflation. In the light of my analysis, 

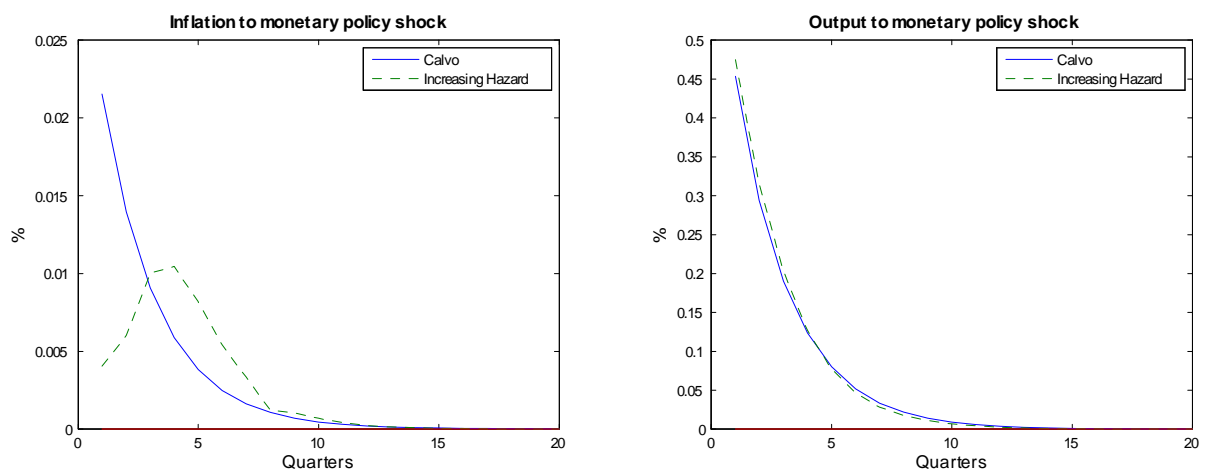

Figure 2: Responses to a monetary policy shock under a contemporary Taylor rule
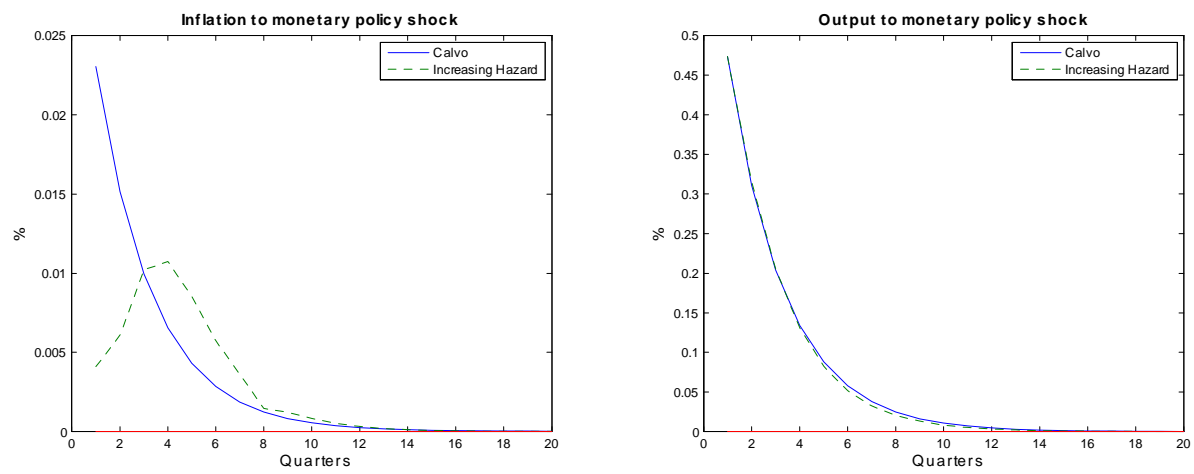

Figure 3: Responses to a montary policy shock under a forward-looking Taylor rule 
the monotonic impulse responses, per se, is not an intrinsic feature of sticky price models, it rather merely results from the restrictive hazard function underlying the Calvo assumption.

\section{Impulse Responses to a Cost-push Shock}

In this section, I discuss the model's responses to a persistent cost-push shock $\left(\rho_{u}=0.5\right)$. First, I discuss it under the contemporary Taylor rule, and then I turn to the forward-looking Taylor rule, which is more consistent with the optimal policy rule derived under the discretionary policy regime with inflation persistence (Clarida et al., 1999).
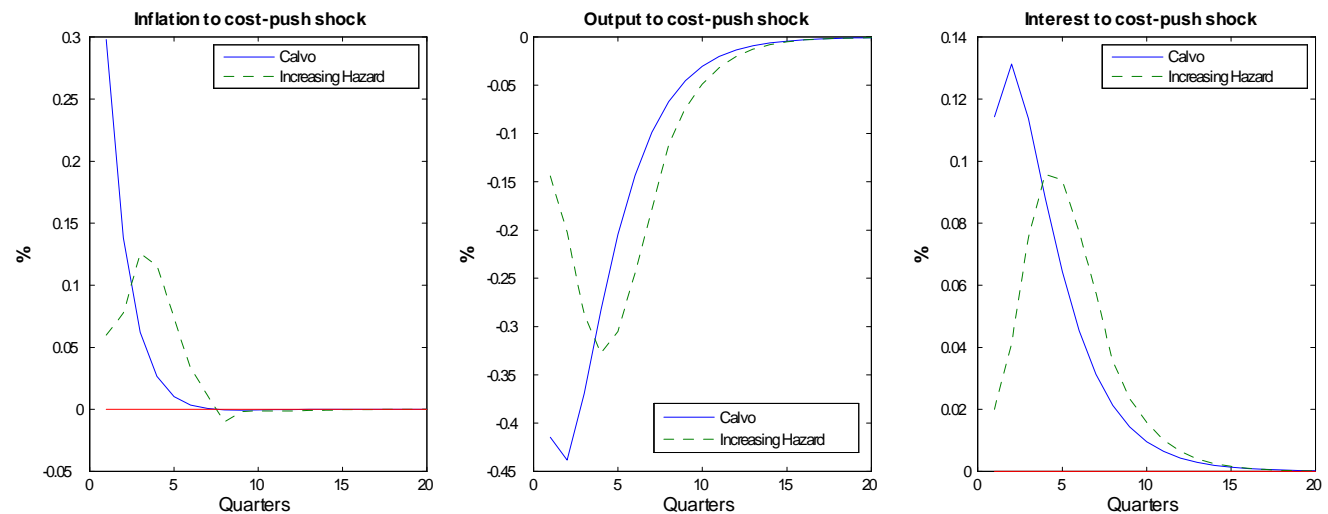

Figure 4: Responses to a transitory cost-push shock under a contemporary Taylor rule

Figure 4 depicts the impulse responses to a $1 \%$ increase in the cost-push shock under the contemporary Taylor rule. I compare impulse response functions generated by the Calvo model to those from the survey evidence motivated increasing-hazard model. Under the contemporary Taylor rule, the increasing-hazard model predicts a better trade-off between inflation and output than the Calvo model. Inflation rises only $0.05 \%$ at the impact in the increasing-hazard model compared to a $0.3 \%$ increase in the Calvo model. The output gap drops by $0.15 \%$ in the increasing-hazard model, but by more than $0.4 \%$ in the Calvo model. The difference in the responses of two models is mainly due to the endogenous inflation inertia introduced by the generalized hazard function, which is missing in the Calvo case. Despite its popularity in monetary policy analysis, the sticky-price model with the Calvo price-setting is often criticized for generating too little inflation inertia (e.g. Fuhrer and Moore, 1995 and Mankiw, 2001). To overcome these weaknesses, theoretically unattractive features, such as the rule-of-thumb price setter (Gali and Gertler, 1999) and inflation indexation (Christiano et al., 2005), are embedded in the pricing behavior. By contrast, the extension of the Calvo sticky price model to a case allowing for more flexible shapes of the hazard function gives the model an endogenous source of inflation inertia. As a result, inflation is strongly anchored to his own past, so that the contemporary Taylor rule need not to react to inflation as aggressively as in the Calvo case.

In figure 5, I depict the impulse responses to a $1 \%$ increase in the cost-push shock under the forward-looking Taylor rule. Under the forward-looking Taylor rule, the increasing-hazard model performs similar to the previous case. Inflation rises about $0.05 \%$ and the output gap drops by $0.13 \%$ at the impact. But the trade-off between inflation and output in the Calvo 

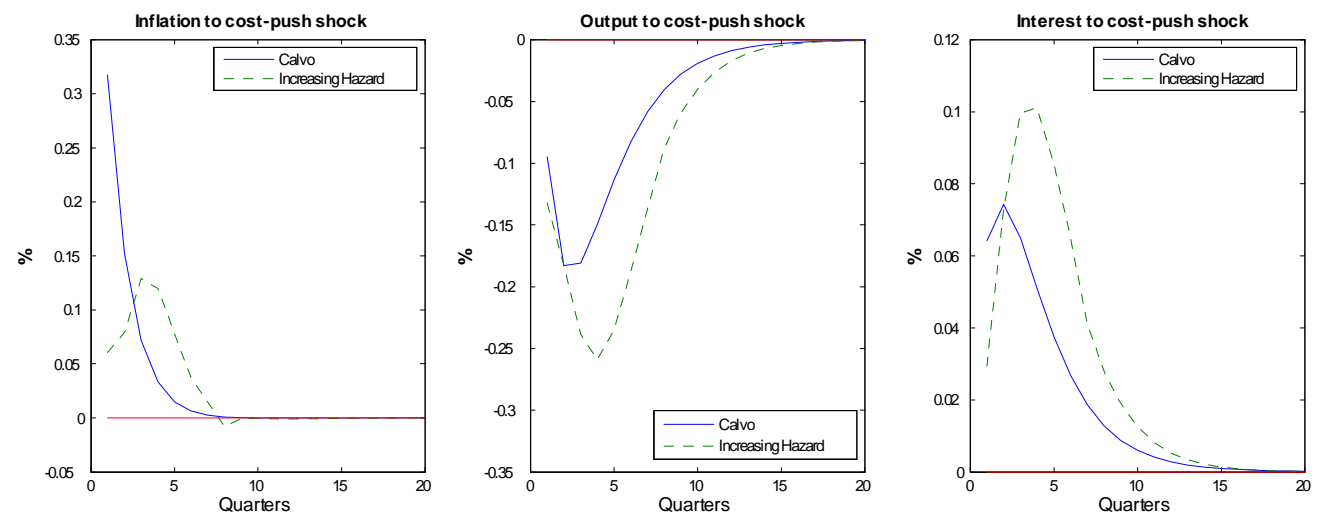

Figure 5: Responses to a persistent cost-push shock under a forward-looking Taylor rule

model improves thanks to the fact that nominal interest rate does not react to current inflation but the expected future inflation. As a result, even though inflation still rises more than $0.3 \%$, but the output gap only declines $0.1 \%$ in the short-run.

\section{Comparison Between Monetary Policy Rules}

In the last two figures, I compare the contemporary and forward-looking rules side by side in each model. In figure (6), impulse responses of inflation, output and interest rate of the Calvo model are compared. In this case, the forward-looking rule significantly outperforms the contemporary rule in terms of the output loss. In the increasing-hazard model, as shown in figure (7), the difference in the responses of the output gap is not as prominent as in the Calvo case, but one can still conclude that the forward-looking rule results in a better inflation-output trade-off.
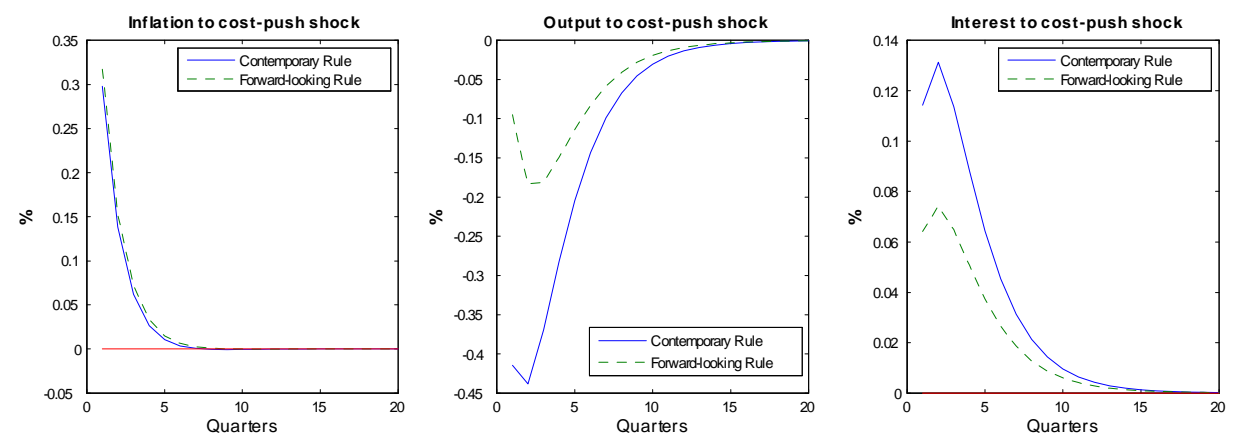

Figure 6: Comparison between two Taylor rules in the Calvo model

All in all, we can conclude that the forward-looking interest rule is superior to the contemporary rule in response to a cost-push shock, consistent with the finding by Clarida et al. (2000). The previous numerical exercises check the robustness of this conclusion under an increasing hazard function. The new insight gained from the exercise is that, when the firm's pricing behavior is characterized by an increasing hazard function as those calculated from the 

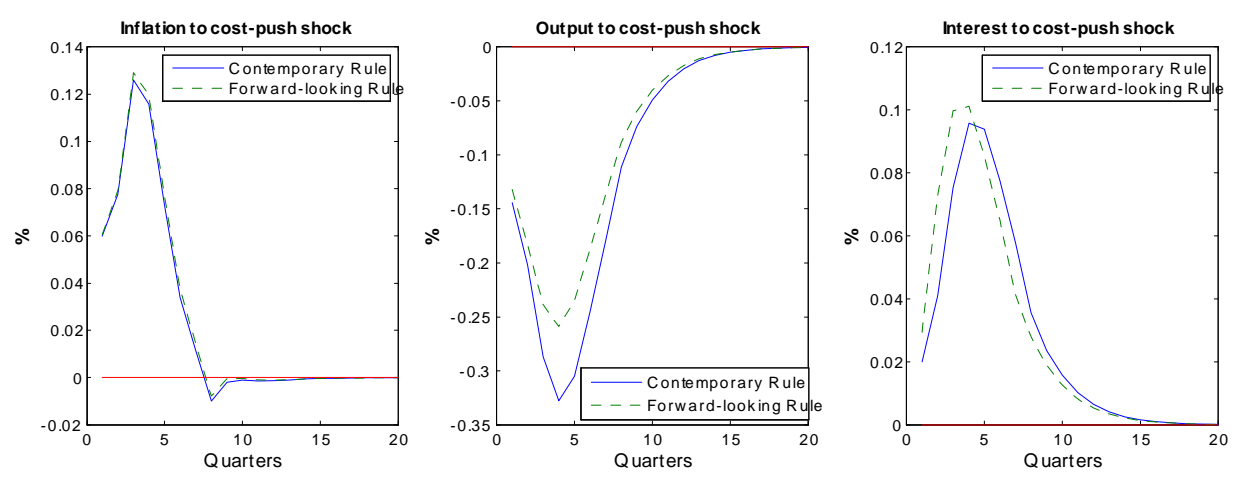

Figure 7: Comparison between two Taylor rules in the increasing-hazard model

survey data, the benefit from switch from the contemporary to the forward-looking rules is less significant.

\section{Conclusion}

The sticky price is an important topic in macroeconomics, because it affects how inflation reacts to changes in monetary policy. This paper addresses this topic in a parsimonious way. Instead of presenting a fully micro-founded sticky price model, I choose a modeling strategy, which is so flexible that it is capable to nest a wide range of sticky price settings. In particular, by allowing for an arbitrary shape of the hazard function, the model's implication is more generally relevant than the model based on a specific sticky price-setting.

The most important result I find in this paper is that the shape of an impulse response of inflation is mainly determined by the shape of the price-duration distribution. Different assumptions about sticky prices lead to different price distributions, which in turn affect how inflation reacts to monetary shocks. In the light of this result, I conclude that the lack of inflation inertia of the New Keynesian models is not intrinsic feature of the model, rather it is to a large extent due to the Calvo staggering assumption, which is solely motivated by its tractability. This paper shows that, once relaxing this restrictive assumption, the sticky price model can generate realistic inflation dynamics.

Several extensions to this model could be interesting for future research. In his seminal paper, Ascari (2004) has shown that trend inflation has important implications for the model's dynamics when the Calvo pricing model is log-linearized around non-zero trend inflation. The basic model presented in the paper can be extended to incorporating positive trend inflation. Combining trend inflation with increasing hazards is an interesting exercise, because, as shown in Ascari (2004) and Cogley and Sbordone (2008), introducing constant or variant trend inflation affects all coefficients, and hence it changes the relative importance between the forward-looking and backward-looking terms in the New Keynesian Phillips curve. As a result, trend inflation exerts a larger impact on inflation dynamics in the increasing-hazard model than it does in the Calvo model. On the empirical aspect, the model can be estimated using the Bayesian technique with the time series data. This exercise allows us to extract valuable information about the price reset hazard function hidden in the aggregate data. 


\section{References}

Altig, D. E., L. J. Christiano, M. Eichenbaum, and J. Lindï£i (2005), Firm-specific capital, nominal rigidities and the business cycle, CEPR Discussion Papers 4858, C.E.P.R. Discussion Papers.

Alvarez, L. J. (2007), What do micro price data tell us on the validity of the new keynesian phillips curve?, Kiel Working Papers 1330, Kiel Institute for the World Economy.

Alvarez, L. J., P. Burriel, and I. Hernando (2005), Do decreasing hazard functions for price changes make any sense?, Working Paper Series 461, European Central Bank.

Ascari, G. (2004), Staggered prices and trend inflation: Some nuisances, Review of Economic Dynamics, 7(3), 642-667.

Blinder, A. S., E. D. Canetti, D. E. Lebow, and J. B. Rudd (1998), Asking about prices - A new approach to understanding price stickiness, Russell Sage Foundation, New York.

Calvo, G. A. (1983), Staggered prices in a utility-maximizing framework, Journal of Monetary Economics, 12(3), 383-98.

Carvalho, C. (2006), Heterogeneity in price stickiness and the real effects of monetary shocks, The B.E. Journal of Macroeconomics, 0(1).

Cecchetti, S. G. (1986), The frequency of price adjustment : A study of the newsstand prices of magazines, Journal of Econometrics, 31(3), 255-274.

Christiano, L. J., M. Eichenbaum, and C. L. Evans (1999), Monetary policy shocks: What have we learned and to what end?, in: J. B. Taylor and M. Woodford (eds.), Handbook of Macroeconomics, vol. 1, Part A, 1 edn., chap. 02, 65-148, Elsevier.

Christiano, L. J., M. Eichenbaum, and C. L. Evans (2005), Nominal rigidities and the dynamic effects of a shock to monetary policy, Journal of Political Economy, 113(1), 1-45.

Clarida, R., J. Gali, and M. Gertler (1999), The science of monetary policy: A new keynesian perspective, Journal of Economic Literature, 37(4), 1661-1707.

Clarida, R., J. Gali, and M. Gertler (2000), Monetary policy rules and macroeconomic stability: Evidence and some theory, The Quarterly Journal of Economics, 115(1), 147-180.

Cogley, T. and A. M. Sbordone (2008), Trend inflation, indexation, and inflation persistence in the new keynesian phillips curve, American Economic Review, 98(5), 2101-26.

Dixon, H. and E. Kara (2010), Can we explain inflation persistence in a way that is consistent with the microevidence on nominal rigidity?, Journal of Money, Credit and Banking, 42(1), $151-170$.

Dotsey, M., R. G. King, and A. L. Wolman (1999), State-dependent pricing and the general equilibrium dynamics of money and output, The Quarterly Journal of Economics, 114(2), 655-690. 
Fuhrer, J. and G. Moore (1995), Inflation persistence, The Quarterly Journal of Economics, $110(1), 127-59$.

Gali, J. and M. Gertler (1999), Inflation dynamics: A structural econometric analysis, Journal of Monetary Economics, 44(2), 195-222.

Goette, L., R. Minsch, and J.-R. Tyran (2005), Micro evidence on the adjustment of sticky-price goods: It's how often, not how much, Discussion Papers 05-20, University of Copenhagen. Department of Economics.

Golosov, M. and R. E. Lucas (2007), Menu costs and phillips curves, Journal of Political Economy, 115, 171-199.

Kiley, M. T. (2002), Partial adjustment and staggered price setting, Journal of Money, Credit and Banking, 34(2), 283-98.

Kimball, M. S. (1995), The quantitative analytics of the basic neomonetarist model, Journal of Money, Credit and Banking, 27(4), 1241-77.

Klenow, P. J. and O. Kryvtsov (2008), State-dependent or time-dependent pricing: Does it matter for recent u.s. inflation?, The Quarterly Journal of Economics, 123(3), 863-904.

Mankiw, N. G. (2001), The inexorable and mysterious tradeoff between inflation and unemployment, Economic Journal, 111(471), C45-61.

Mankiw, N. G. and R. Reis (2002), Sticky information versus sticky prices: A proposal to replace the new keynesian phillips curve, The Quarterly Journal of Economics, 117(4), $1295-1328$.

Mash, R. (2003), New keynesian microfoundations revisited: A calvo-taylor-rule-of-thumb model and optimal monetary policy delegation, Economics Series Working Papers 174, University of Oxford, Department of Economics.

Mash, R. (2004), Optimising microfoundations for inflation persistence, Economics Series Working Papers 183, University of Oxford, Department of Economics.

Nakamura, E. and J. Steinsson (2008a), Five facts about prices: A reevaluation of menu cost models, The Quarterly Journal of Economics, 123(4), 1415-1464.

Nakamura, E. and J. Steinsson (2008b), Monetary non-neutrality in a multi-sector menu cost model, NBER Working Papers 14001, National Bureau of Economic Research, Inc.

Sheedy, K. D. (2010), Intrinsic inflation persistence, Journal of Monetary Economics, 57(8), 1049-1061.

Taylor, J. B. (1980), Aggregate dynamics and staggered contracts, Journal of Political Economy, 88(1), 1-23.

Taylor, J. B. (1993), Discretion versus policy rules in practice, Carnegie-Rochester Conference Series on Public Policy, 39, 195-214. 
Vavra, J. (2010), The empirical price duration distribution and monetary non-neutrality, Working paper series, SSRN eLibrary.

Whelan, K. (2007), Staggered price contracts and inflation persistence: Some general results, International Economic Review, 48(1), 111-145.

Wolman, A. L. (1999), Sticky prices, marginal cost, and the behavior of inflation, Economic Quarterly, 3(Fall), 29-48.

Woodford, M. (2003), Interest and Prices, Princeton University Press.

Yao, F. (2009), The cost of tractability and the calvo pricing assumption, SFB 649 Discussion Papers 042, Humboldt University, Berlin, Germany.

Yao, F. (2011), Sticky information versus sticky prices: A horse race under a general pricesetting scheme, ssrn working paper, University of Erlangen and Nuremberg, available at http://ssrn.com/paper $=1903783$. 


\section{Proof of Proposition 1}

First, based on the assumption that nominal money supply follows an $A R(1)$ process

$$
m_{t}=\rho m_{t-1}+\epsilon_{t}, \quad \text { where } \epsilon_{t} \backsim i . i . d .\left(0, \sigma_{m}^{2}\right),
$$

The impulse response function of nominal money supply to an innovation $\epsilon_{t}$ is

$$
\operatorname{IR}\left(m_{t+i}\right)=\rho^{i} .
$$

Impulse response function under the sticky-price model Next, to derive the impulse responses of optimal price under the SP model, we use the equation (8)

$$
\begin{aligned}
x_{t} & =\sum_{k=0}^{\infty} \frac{S_{k}}{\Psi} E_{t}\left[m_{t+k}\right], \\
\text { where } \Psi & =\sum_{k=0}^{\infty} S_{k} .
\end{aligned}
$$

Using the definition of impulse response function, I have

$$
\begin{aligned}
I R\left(x_{t+n}\right) \epsilon_{t} & =E_{t}\left(x_{t+n}\right)-E_{t-1}\left(x_{t+n}\right) \\
& =\sum_{k=0}^{\infty} \frac{S_{k}}{\Psi}\left[E_{t}\left(m_{t+n+k}\right)-E_{t-1}\left(m_{t+n+k}\right)\right] \\
& =\sum_{k=0}^{\infty} \frac{S_{k}}{\Psi} I R\left(m_{t+k+n}\right) \epsilon_{t} \\
& =\sum_{k=0}^{\infty} \frac{S_{k}}{\Psi} \rho^{k+n} \epsilon_{t} .
\end{aligned}
$$

Plugging (22) into (23), it yields

$$
\operatorname{IR}\left(x_{t+n}\right)=\sum_{k=0}^{\infty} \frac{S_{k} \rho^{k}}{\Psi} \rho^{n} .
$$

Following the aggregate price equation (9) under the SP model, I can derive impulse response function of the aggregate price as follows

$$
\begin{aligned}
I R\left(p_{t+i}\right) \epsilon_{t} & =E_{t}\left(p_{t+i}\right)-E_{t-1}\left(p_{t+i}\right) \\
& =\sum_{j=0}^{i} \theta_{j} E_{t}\left(x_{t-j+i}\right)-\sum_{j=0}^{i} \theta_{j} E_{t-1}\left(x_{t-j+i}\right) \\
& =\sum_{j=0}^{i} \theta_{j}\left[E_{t}\left(x_{t-j+i}\right)-E_{t-1}\left(x_{t-j+i}\right)\right] \\
& =\sum_{j=0}^{i} \theta_{j} I R\left(x_{t-j+i}\right) \epsilon_{t} . \\
\operatorname{IR}\left(p_{t+i}\right) & =\sum_{j=0}^{i} \theta_{j} \operatorname{IR}\left(x_{t-j+i}\right) .
\end{aligned}
$$


Finally, plugging (24) into (25), it yields

$$
\begin{aligned}
I R\left(p_{t+i}\right) & =\sum_{j=0}^{i} \theta_{j}\left[\rho^{i-j} \sum_{k=0}^{\infty} \frac{S_{k} \rho^{k}}{\Psi}\right] \\
& =\underbrace{\sum_{k=0}^{\infty} \frac{S_{k} \rho^{k}}{\Psi} \sum_{j=0}^{i} \theta_{j} \rho^{i-j}}_{\bar{F}} \\
& =\bar{F} \sum_{j=0}^{i} \theta_{j} \rho^{i-j}
\end{aligned}
$$




\section{Proof of Proposition 2}

First, based on the assumption that nominal money growth rate follows an $A R(1)$ process

$$
\Delta m_{t}=\rho \Delta m_{t-1}+\epsilon_{t}, \text { where } \epsilon_{t} \backsim i . i . d .\left(0, \sigma_{m}^{2}\right),
$$

we can derive the impulse response function of nominal money growth rate to an innovation $\epsilon_{t}$ as

$$
I R\left(\Delta m_{t+i}\right)=\rho^{i} .
$$

Next, define inflation as $\pi_{t}=p_{t}-p_{t-1}$ and the impulse response function of inflation is obtained by

$$
\begin{aligned}
\operatorname{IR}\left(\pi_{t+i}\right) \epsilon_{t} & =E_{t}\left(\pi_{t+i}\right)-E_{t-1}\left(\pi_{t+i}\right) \\
& =E_{t}\left(p_{t+i}-p_{t+i-1}\right)-E_{t-1}\left(p_{t+i}-p_{t+i-1}\right) \\
& =\left[E_{t}\left(p_{t+i}\right)-E_{t-1}\left(p_{t+i}\right)\right]-\left[E_{t}\left(p_{t+i-1}\right)-E_{t-1}\left(p_{t+i-1}\right)\right] \\
& =\operatorname{IR}\left(p_{t+i}\right) \epsilon_{t}-\operatorname{IR}\left(p_{t+i-1}\right) \epsilon_{t} \\
\operatorname{IR}\left(\pi_{t+i}\right) & =\operatorname{IR}\left(p_{t+i}\right)-\operatorname{IR}\left(p_{t+i-1}\right) .
\end{aligned}
$$

Impulse response function under the sticky-price model Under the SP model, the impulse responses of the change in optimal prices is

$$
\begin{aligned}
I R\left(x_{t+n}-x_{t+n-1}\right) \epsilon_{t} & =E_{t}\left(x_{t+n}-x_{t+n-1}\right)-E_{t-1}\left(x_{t+n}-x_{t+n-1}\right) \\
& =\sum_{k=0}^{\infty} \frac{S_{k}}{\Psi}\left[E_{t}\left(\Delta m_{t+n+k}\right)-E_{t-1}\left(\Delta m_{t+n+k}\right)\right] \\
& =\sum_{k=0}^{\infty} \frac{S_{k}}{\Psi} I R\left(\Delta m_{t+k+n}\right) \epsilon_{t} \\
& =\sum_{k=0}^{\infty} \frac{S_{k}}{\Psi} \rho^{k+n} \epsilon_{t} . \\
I R\left(x_{t+n}-x_{t+n-1}\right) & =\sum_{k=0}^{\infty} \frac{S_{k} \rho^{k}}{\Psi} \rho^{n}
\end{aligned}
$$

Following (25), which holds independent of nature of the shock, I can derive impulse response function of inflation from equation (28)

$$
\begin{aligned}
\operatorname{IR}\left(\pi_{t+i}\right) & =\operatorname{IR}\left(p_{t+i}\right)-\operatorname{IR}\left(p_{t+i-1}\right) \\
& =\sum_{j=0}^{i} \theta_{j} \operatorname{IR}\left(x_{t-j+i}\right)-\sum_{j=0}^{i} \theta_{j} \operatorname{IR}\left(x_{t-j+i-1}\right) \\
& =\sum_{j=0}^{i} \theta_{j} \operatorname{IR}\left(x_{t-j+i}-x_{t-j+i-1}\right)
\end{aligned}
$$


Finally, plugging (29) into (30), it yields

$$
\begin{aligned}
I R\left(\pi_{t+i}\right) & =\sum_{j=0}^{i} \theta_{j}\left[\rho^{i-j} \sum_{k=0}^{\infty} \frac{S_{k} \rho^{k}}{\Psi}\right] \\
& =\underbrace{\sum_{k=0}^{\infty} \frac{S_{k} \rho^{k}}{\Psi}}_{\bar{F}} \sum_{j=0}^{i} \theta_{j} \rho^{i-j} \\
& =\bar{F} \sum_{j=0}^{i} \theta_{j} \rho^{i-j}
\end{aligned}
$$

